\title{
Sistem Pendukung Keputusan Penilaian Kinerja Karyawan Menerapkan Kombinasi Metode Simple Additive Weighting (SAW) dengan Rank Order Centroid (ROC)
}

\author{
Muliati Badaruddin \\ Prodi Sistem Informasi, STMIK Ichsan Gorontalo, Gorontalo, Indonesia \\ Email: ${ }^{1}$ muliati.badaruddin@ @stmik-ichsan.ac.id
}

\begin{abstract}
Abstrak
Dalam penelitian ini dibahas kombinasi metode Rank Order Centroid(ROC) dan Simple Additive Weighting (SAW) untuk menghasilkan keputusan manager perusahaan dalam penilaian kinerja karyawan. Hasil penilaian kinerja karyawan diharapkan menjadi lebih efektif dan objektif dikarenakan dukungan sistem pendukung keputusan yang digunakan. Banyak penelitian yang dilakukan dalam penilaian kinerja dengan menggunakan metode Simple Additive Weighting, namun belum atau tidak menggunakan pembobotan yang baik. Dengan kombinasi metode pembobotan dan perangkingan maka hasil keputusan dapat dipastikan akan menjadi lebih efektif.
\end{abstract}

Kata Kunci: Simple Additive Weighting, SAW, Rank Order Centroid, ROC, Kinerja, Karyawan, SPK

\section{Abstract}

This research discusses the combination of Rank Order Centroid (ROC) and Simple Additive Weighting (SAW) methods to produce company manager's decisions in evaluating employee performance. The results of employee performance appraisal are expected to be more effective and objective due to the support of the decision support system used. Many studies have been conducted in performance appraisal using the Simple Additive Weighting method, but have not or do not use good weighting. With a combination of weighting and ranking methods, the outcome of the decision will certainly be more effective.

Keywords: Simple Additive Weighting, SAW, Rank Order Centroid, ROC, Performance, Employee, DSS

\section{PENDAHULUAN}

Penerapan teknologi informasi yang berkembang hingga saat ini semakin dirasakan manfaatkan disemua kalangan, penerapan aplikasi-aplikasi yang mendukung keputusan baik semi terstruktur maupun yang terstruktur memberikan efektifitas terhadap keputusan yang dihasilkan manager perusahaan. Sehingga memudahkan penilaian terhadap kinerja karyawan diperusahaan tersebut. Penilaian kinerja karyawan sangat penting dilakukan, agar pemberian insentif yang dilakukan oleh manager perusahaan tepat sasaran.

Beberapa tujuan dilakukannya penilaian terhadap kinerja karyawan yaitu untuk pemberian insentif kerja, promosi kenaikan jabatan, peningkatan kualitas kerja, motivasi terhadap karyawan, evaluasi atas hasil kerja yang dilakukan, dan lainnya. Besarnya manfaat yang diberikan terhadap penilaian kinerja maka hal ini sangat penting dilakukan oleh manager perusahaan. Penerapan teknologi yang mendukung keputusan karyawan tersebut dapat digunakan dengan menerapkan Sistem Pendukung Keputusan (SPK)[1].

Sistem Pendukung Keputusan merupakan suatu sistem berbasis komputer yang membantu manager dalam menyelesaikan masalah baik terstruktur maupun tidak terstruktur dengan menggunakan data dan metode[2]-[4]. Keputusan yang baik dihasilkan dari proses yang objektif dan hal ini mampu diselesaikan dengan penggunakan SPK [5]. Penerapan metode metode dalam penghasilan keputusan perlu di lakukan agar hasil yang diberikan dapat dipertanggung jawabkan dengan baik. Hingga saat ini penerapan metode dalam sistem pendukung keputusan banyak dilakukan di kalangan peneliti-peneliti, beberapa metode tersebut diantaranya Simple Additive Weighting[6], TOPSIS[7], [8], ELECTRE[9]-[11], MOORA[12]-[14], ARAS[15], [16].

Pada penelitian ini penulis menggunakan metode Simple Additive Weighting (SAW). Metode ini sangat mudah dan sederhana dalam menghasilkan keputusan. Namun dalam penerapan metode SAW bobot masih dihasilkan dengan pemberian nilai langsung dalam pemrosesan perangkingan. Hal ini tentu memberikan kelemahan besar dalam perangkingan menggunakan metode SAW. Agar pembobotan terhadap kriteria menjadi lebih baik, penulis menggunakan metode Rank Order Centroid (ROC). ROC merupakan metode sederhana yang dapat menghasilkan nilai bobot terhadap beberapa kriteria yang digunakan[15].

\section{METODE PENELITIAN}

\subsection{Karyawan}

Menurut undang-undang No.14 Tahun 1969 tentang Pokok Tenaga Kerja, karyawan merupakan orang yang mampu melaksanakan pekerjaan, baik didalam maupun diluar hubungan kerja guna menghasilkan jasa ataupun barang untuk memenuhi kebutuhan masyarakat. Karyawan merupakan seseorang yang dapat melakukan pekerjaan 
serta memberikan hasil kerjanya kepada pengusaha atau instansi tempat karyawan bekerja, dimana hasil kerjanya sesuai dengan profesi atau pekerjaan atas keahlian yang dibidanginya.

\subsection{Rank Order Centroid (ROC)}

Rank Order Centroid (ROC) merupakan metode dalam memberikan hasil bobot yang dibutuhkan dalam perangkingan pada sistem pendukung keputusan. Penerapan metode ROC cukup mudah. ROC bekerja dengan menitikberatkan bahwa kriteria pertama lebih penting dibanding kriteria kedua, kriteria kedua lebih penting dibanding kriteria ke tiga, begitu selanjutnya[15], [17]. Sehingga dapat digambarkan kepentingan kriteria seperti dibawah ini:

$$
\mathrm{C}_{1}>\mathrm{C}_{2}>\mathrm{C}_{3}>\mathrm{C}_{\mathrm{m}}
$$

Nilai bobot(W), dapat dihasilkan dengan berikut:

$$
W_{m}=\frac{1}{m} \sum_{1=1}^{m}\left(\frac{1}{i}\right)
$$

\subsection{Simple Additive Weighting}

Metode Simple Additive Weighting merupakan metode yang dapat melakukan perangkingan dengan penjumlahan terbobot pada setiap nilai alternatif[6], [18], [19]. Metode ini cukup mudah dalam proses perhitungannya. Beberapa langkah dalam penerapan metode SAW[20], [21], seperti pada langkah berikut ini:

1. Mempersiapkan matrik keputusan

$$
=\left[\begin{array}{cccc}
x_{11} & x_{12} & \cdot & x_{1 n} \\
x_{21} & x_{11} & \cdot & x_{2 n} \\
\cdot & \cdot & \cdot & \cdot \\
x_{m 1} & x_{m 1} & \cdot & x_{m n}
\end{array}\right]
$$

2. Menormalisasikan matrik keputusan

Untuk kriteria benefit menggunakan persamaan berikut.

$$
R_{i j}=\frac{X_{i j}}{\operatorname{Max} X_{i j}}
$$

Untuk kriteria cost menggunakan persamaan berikut.

$$
R_{i j}=\frac{\operatorname{Min} X_{i j}}{X_{i j}}
$$

3. Melakukan perangkingan

$$
V_{i}=\sum_{j=1}^{n} W_{j} \cdot R_{i j}
$$

Alternatif yang terbaik merupakan alternatif yang memiliki nilai Vi tertinggi.

\section{ANALISA DAN PEMBAHASAN}

Dalam penerapan sistem pendukung keputusan, dibutuhkan alternatif-alternatif, kriteria serta bobot dari kriteria yang digunakan sebagai data dalam menghasilkan suatu keputusan. Berikut pada tabel 1, merupakan kriteria yang merupakan syarat-syarat yang digunakan untuk penilaian kinerja karyawan. Sedangkan pada tabel 2, merupakan alternatif karyawan perusahaan yang akan dinilai kinerjanya pada penelitian ini.

Tabel 1. Kriteria Penilaian Kinerja

\begin{tabular}{clc}
\hline Kriteria & Keterangan & Jenis \\
\hline $\mathrm{C}_{1}$ & Kualitas Kerja & Benefit \\
$\mathrm{C}_{2}$ & Disiplin & Benefit \\
$\mathrm{C}_{3}$ & Kerjasama & Benefit \\
$\mathrm{C}_{4}$ & Loyalitas & Benefit \\
$\mathrm{C}_{5}$ & Teguran & Cost \\
\hline
\end{tabular}

Tabel 2. Alternatif Karyawan

\begin{tabular}{cccccc}
\hline Alternatif & $\begin{array}{c}\text { Kualitas } \\
\text { Kerja }\left(\mathbf{C}_{\mathbf{1}}\right)\end{array}$ & Disiplin $\left(\mathbf{C}_{2}\right)$ & $\begin{array}{c}\text { Kerjasama } \\
\left(\mathbf{C}_{\mathbf{3}}\right)\end{array}$ & $\begin{array}{c}\text { Loyalitas } \\
\left(\mathbf{C}_{\mathbf{4}}\right)\end{array}$ & $\begin{array}{c}\text { Teguran } \\
\left(\mathbf{C}_{\mathbf{5}}\right)\end{array}$ \\
\hline $\mathrm{A}_{1}$ & Baik & Sangat Baik & Cukup Baik & Sangat Baik & Tidak Pernah \\
$\mathrm{A}_{2}$ & Sangat Baik & Baik & Baik & Cukup Baik & Tidak Pernah \\
$\mathrm{A}_{3}$ & Sangat Baik & Baik & Baik & Baik & Tidak Pernah \\
$\mathrm{A}_{4}$ & Baik & Sangat Baik & Sangat Baik & Cukup Baik & Tidak Pernah \\
\hline
\end{tabular}




\begin{tabular}{cccccc}
\hline Alternatif & $\begin{array}{c}\text { Kualitas } \\
\text { Kerja }\left(\mathbf{C}_{\mathbf{1}}\right)\end{array}$ & Disiplin $\left(\mathbf{C}_{2}\right)$ & $\begin{array}{c}\text { Kerjasama } \\
\left(\mathbf{C}_{\mathbf{3}}\right)\end{array}$ & $\begin{array}{c}\text { Loyalitas } \\
\left(\mathbf{C}_{\mathbf{4}}\right)\end{array}$ & $\begin{array}{c}\text { Teguran } \\
\left(\mathbf{C}_{5}\right)\end{array}$ \\
\hline $\mathrm{A}_{5}$ & Sangat Baik & Baik & Baik & Baik & Tidak Pernah \\
$\mathrm{A}_{6}$ & Kurang Baik & Cukup Baik & Baik & Sangat Baik & Pernah \\
$\mathrm{A}_{7}$ & Cukup Baik & Baik & Baik & Baik & Tidak Pernah \\
$\mathrm{A}_{8}$ & Baik & Cukup Baik & Baik & Sangat Baik & Tidak Pernah \\
$\mathrm{A}_{9}$ & Kurang Baik & Baik & Baik & Baik & Pernah \\
$\mathrm{A}_{10}$ & Baik & Sangat Baik & Kurang Baik & Baik & Pernah \\
\hline
\end{tabular}

Pada tabel 1 kriteria diatas, belum memiliki bobot, untuk itu tahap pertama yang dilakukan yaitu menentukan nilai bobot pada tiap tiap kriteria. Hal ini dengan menggunakan metode ROC, berikut perhitungan dengan menerapkan metode ROC (persamaan 2).

$W_{1}=\frac{1+\frac{1}{2}+\frac{1}{3}+\frac{1}{4}+\frac{1}{5}}{5}=0,457$

$W_{2}=\frac{0+\frac{1}{2}+\frac{1}{3}+\frac{1}{4}+\frac{1}{5}}{5}=0,257$

$W_{3}=\frac{0+0+\frac{1}{3}+\frac{1}{4}+\frac{1}{5}}{5}=0,156$

$W_{4}=\frac{0+0+0+\frac{1}{4}+\frac{1}{5}}{5}=0,090$

$W_{5}=\frac{0+0+0+0+\frac{1}{5}}{5}=0,040$

Hasil dari perhitungan pembobotan diatas dapat dilihat pada tabel 3 .

Tabel 3. Nilai Bobot

\begin{tabular}{cc}
\hline Kriteria & Bobot \\
\hline $\mathrm{C}_{1}$ & 0,457 \\
$\mathrm{C}_{2}$ & 0,257 \\
$\mathrm{C}_{3}$ & 0,156 \\
$\mathrm{C}_{4}$ & 0,090 \\
$\mathrm{C}_{5}$ & 0.040 \\
\hline
\end{tabular}

Pada tabel 2 nilai dari tiap-tiap kriteria pada setiap alternatif dibobotkan dengan menggunakan tabel 4 dan 5, sebagai berikut:

Tabel 4. Pembobotan Nilai Kriteria $\mathrm{C}_{1}-\mathrm{C}_{4}$

\begin{tabular}{lc}
\hline Keterangan & Bobot \\
\hline Sangat Baik & 5 \\
Baik & 4 \\
Cukup Baik & 3 \\
Kurang Baik & 2 \\
Tidak Baik & 1 \\
\hline
\end{tabular}

Tabel 5. Pembobotan Nilai Kriteria $C_{5}$

\begin{tabular}{lc}
\hline Keterangan & Bobot \\
\hline Tidak Pernah & 1 \\
Pernah & 2 \\
\hline
\end{tabular}

Sehingga hasil dari pembobotan dapat dilihat pada tabel 6 sebagai berikut:

Tabel 6. Rating Kecocokan

\begin{tabular}{cccccc}
\hline Alternatif & $\left(\mathbf{C}_{\mathbf{1}}\right)$ & $\left(\mathbf{C}_{\mathbf{2}}\right)$ & $\left(\mathbf{C}_{\mathbf{3}}\right)$ & $\left(\mathbf{C}_{\mathbf{4}}\right)$ & $\left(\mathbf{C}_{\mathbf{5}}\right)$ \\
\hline $\mathrm{A}_{1}$ & 4 & 5 & 3 & 5 & 1 \\
$\mathrm{~A}_{2}$ & 5 & 4 & 4 & 3 & 1 \\
$\mathrm{~A}_{3}$ & 5 & 4 & 4 & 4 & 1 \\
$\mathrm{~A}_{4}$ & 4 & 5 & 5 & 3 & 1 \\
$\mathrm{~A}_{5}$ & 5 & 4 & 4 & 4 & 1 \\
\hline
\end{tabular}




\begin{tabular}{cccccc}
\hline Alternatif & $\left(\mathbf{C}_{\mathbf{1}}\right)$ & $\left(\mathbf{C}_{2}\right)$ & $\left(\mathbf{C}_{\mathbf{3}}\right)$ & $\left.\mathbf{( C}_{\mathbf{4}}\right)$ & $\left(\mathbf{C}_{5}\right)$ \\
\hline $\mathrm{A}_{6}$ & 2 & 3 & 4 & 5 & 2 \\
$\mathrm{~A}_{7}$ & 3 & 4 & 4 & 4 & 1 \\
$\mathrm{~A}_{8}$ & 4 & 3 & 4 & 5 & 1 \\
$\mathrm{~A}_{9}$ & 2 & 4 & 4 & 4 & 2 \\
$\mathrm{~A}_{10}$ & 4 & 5 & 2 & 4 & 2 \\
\hline
\end{tabular}

Setelah data rating kecocokan telah diperoleh, maka dilakukan perhitungan perangkingan dengan menerapkan metode Simple Additive Weighting (SAW). Langkah awal dengan menyiapkan matrik keputusan(persamaan 3), sebagai berikut:

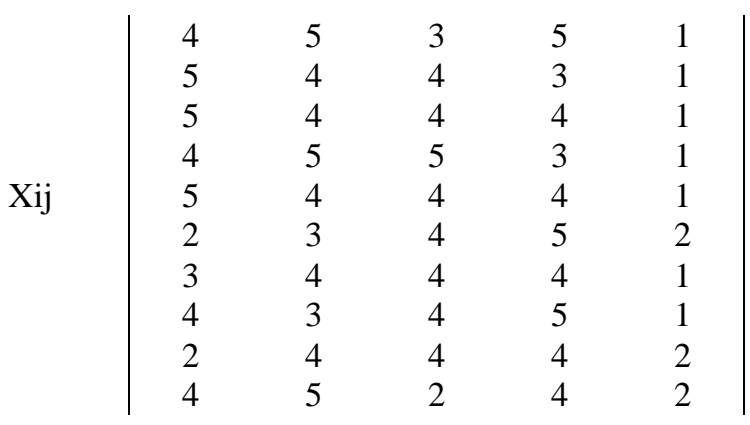

Langkah selanjutnya menormalisasikan matrik keputusan dengan menggunakan persamaan ke 4 dan 5 . Hasil yang diperoleh seperti pada matrik Rij sebagai berikut.

Rij $\quad\left|\begin{array}{ccccc}0.8 & 1 & 0.6 & 1 & 1 \\ 1 & 0.8 & 0.8 & 0.6 & 1 \\ 1 & 0.8 & 0.8 & 0.8 & 1 \\ 0.8 & 1 & 1 & 0.6 & 1 \\ 1 & 0.8 & 0.8 & 0.8 & 1 \\ 0.4 & 0.6 & 0.8 & 1 & 0.5 \\ 0.6 & 0.8 & 0.8 & 0.8 & 1 \\ 0.8 & 0.6 & 0.8 & 1 & 1 \\ 0.4 & 0.8 & 0.8 & 0.8 & 0.5 \\ 0.8 & 1 & 0.4 & 0.8 & 0.5\end{array}\right|$

Berikutnya menentukan Preferensi akhir dengan menggunakan persamaan 6, sehingga hasil akhir dapat dilihat pada tabel 7 .

Tabel 7. Hasil Preferensi Akhir

\begin{tabular}{ccl}
\hline Alternatif & Nilai Vi & Keterangan \\
\hline $\mathrm{A}_{3}$ & 0.8994 & Sangat Baik \\
$\mathrm{A}_{5}$ & 0.8994 & Sangat Baik \\
$\mathrm{A}_{2}$ & 0.8814 & Sangat Baik \\
$\mathrm{A}_{4}$ & 0.8726 & Sangat Baik \\
$\mathrm{A}_{1}$ & 0.8462 & Sangat Baik \\
$\mathrm{A}_{10}$ & 0.777 & Cukup Baik \\
$\mathrm{A}_{8}$ & 0.7746 & Cukup Baik \\
$\mathrm{A}_{7}$ & 0.7166 & Cukup Baik \\
$\mathrm{A}_{9}$ & 0.6052 & Kurang Baik \\
$\mathrm{A}_{6}$ & 0.5718 & Kurang Baik \\
\hline
\end{tabular}

Pada tabel 7 dapat dilihat karyawan yang memiliki nilai dibawah 0.7 merupakan karyawan yang memiliki kinerja yang Kurang Baik, di antara atau sama dengan 0.7 dan dibawah 0.8 memiliki nilai Cukup Baik dan yang diatas atau sama dengan 0.8 memiliki kinerja yang Sangat Baik. Dari hasil perhitungan pada tabel 7 tersebut, merupakan dasar bagi manager perusahaan untuk menilai karyawan dan memutuhkan karyawan yang akan diberikan insentif, promosi kenaikan jabatan atau reward.

\section{KESIMPULAN}

Dari penelitian yang dihasilkan diperoleh kesimpulan:

1. Sistem Pendukung Keputusan memberikan keputusan bagi manager untuk menghasilkan keputusan yang objectif, sehingga dapat meningkatkan efektifitas keputusan yang dihasilkan. 
2. Penerapan kombinasi ROC dan SAW memberikan keputusan yang lebih baik bila dibandingkan dengan pembobotan yang dihasilkan tanpa proses perhitungan.

\section{REFERENCES}

[1] Kusrini, Konsep dan Aplikasi Sistem Pendukung Keputusan. 2007.

[2] D. Nofriansyah, Konsep Data Mining Vs Sistem Pendukung Keputusan. 2015.

[3] D. Nofriansyah and S. Defit, Multi Criteria Decision Making (MCDM) pada Sistem Pendukung Keputusan. 2018.

[4] S. Kusumadewi, S. Hartati, A. Harjoko, and R. Wardoyo, Fuzzy Multi-Attribute Decision Making (Fuzzy MADM). Yogyakarta: Graha Ilmu, 2006.

[5] E. Turban, J. E. Aronson, and T. Liang, "Decision Support Systems and Intelligent Systems."

[6] S. H. Sahir, R. Rosmawati, and K. Minan, "Simple Additive Weighting Method to Determining Employee Salary Increase Rate," Int. J. Sci. Res. Sci. Technol., vol. 3, no. 8, pp. 42-48, 2017.

[7] G. Ginting, Fadlina, Mesran, A. P. U. Siahaan, and R. Rahim, "Technical Approach of TOPSIS in Decision Making," Int. J. Recent Trends Eng. Res., vol. 3, no. 8, pp. 58-64, 2017.

[8] Jasri, D. Siregar, and R. Rahim, "Decision Support System Best Employee Assessments with Technique for Order of Preference by Similarity to Ideal Solution," Int. J. Recent TRENDS Eng. Res., vol. 3, no. 3, pp. 6-17, 2017.

[9] I. Saputra, S. I. Sari, and Mesran, "PENERAPAN ELIMINATION AND CHOICE TRANSLATION REALITY ( ELECTRE ) DALAM PENENTUAN KULKAS TERBAIK,” KOMIK (Konferensi Nas. Teknol. Inf. dan Komputer), vol. I, pp. 295-305, 2017.

[10] A. Yanie et al., "Web Based Application for Decision Support System with ELECTRE Method," in Journal of Physics: Conference Series, 2018, vol. 1028, no. 1 .

[11] I. Dahanum and T. Zebua, "Sistem Pendukung Keputusan Pemilihan Internet Service Provider Menerapkan Metode Elimination and Choice Translation Reality ( Electre )," KOMIK (Konferensi Nas. Teknol. Inf. dan Komputer), vol. I, pp. 248-255, 2017.

[12] D. Assrani, N. Huda, R. Sidabutar, I. Saputra, and O. K. Sulaiman, "Penentuan Penerima Bantuan Siswa Miskin Menerapkan Metode Multi Objective Optimization on The Basis of Ratio Analysis (MOORA)," Penentuan Penerima Bantu. Siswa Miskin Menerapkan Metod. Multi Object. Optim. Basis Ratio Anal., vol. 5, no. 2407-389X (Media Cetak), pp. 1-5, 2018.

[13] J. Afriany, L. Ratna, S. Br, I. Julianty, and E. L. Nainggolan, "Penerapan MOORA Untuk Mendukung Efektifitas Keputusan Manajemen Dalam Penentuan Lokasi SPBU,” vol. 5, no. 2, pp. 161-166, 2018.

[14] N. W. Al-Hafiz, Mesran, and Suginam, "Sistem Pendukung Keputusan Penentukan Kredit Pemilikan Rumah Menerapkan MultiObjective Optimization on the Basis of Ratio Analysis ( Moora )," KOMIK (Konferensi Nas. Teknol. Inf. dan Komputer), vol. I, no. 1, pp. 306-309, 2017.

[15] Mesran, J. Afriany, and S. H. Sahir, "Efektifitas Penilaian Kinerja Karyawan Dalam Peningkatan Motivasi Kerja Menerapkan Metode Rank Order Centroid (ROC) dan Additive Ratio Assessment (ARAS)," in Seminar Nasional Riset Information Science (SENARIS), 2019, no. September, pp. 813-821.

[16] E. K. Zavadskas and Z. Turskis, “A new additive ratio assessment ( ARAS ) method in multicriteria decision - making,” vol. 8619, 2011.

[17] N. Astiani, D. Andreswari, and Y. Setiawan, "Aplikasi Sistem Pendukung Keputusan Tanaman Obat Herbal Untuk Berbagai Penyakit Dengan Metode Roc (Rank Order Centroid) Dan Metode Oreste Berbasis Mobile Web," J. Inform., vol. 12, no. 2, 2016.

[18] M. D. L. Siahaan, Elviwani, A. B. Surbakti, A. H. Lubis, and A. P. U. Siahaan, "Implementation of Simple Additive Weighting Algorithm in Particular Instance,” Int. J. Sci. Res. Sci. Technol., vol. 3, no. 6, pp. 442-447, 2017.

[19] R. T. Utami, D. Andreswari, and Y. Setiawan, "Implementasi Metode Simple Additive Weighting (SAW) dengan pembobotan Rank Order Centroid(ROC) Dalam Pengambilan Keputusan Untuk Seleksi Jasa Leasing Mobil,” J. Rekursif, vol. 4, no. 2, pp. 209-221, 2016.

[20] R. Fauzan, Y. Indrasary, and N. Muthia, "Sistem Pendukung Keputusan Penerimaan Beasiswa Bidik Misi di POLIBAN dengan Metode SAW Berbasis Web," J. Online Inform., vol. 2, no. 2, p. 79, 2018.

[21] Y. M. Kristania, "Implementasi kombinasi metode ahp dan saw dalam pendukung keputusan penentuan kredit perumahan rakyat," $J$. Telemat., vol. 11, no. 1, pp. 65-78, 2018. 